\title{
Review of Gardasil
}

\author{
Diane M Harper ${ }^{1 *}$, Stephen L. Vierthaler ${ }^{2}$ and Jennifer A Santee ${ }^{3}$
}

${ }^{1}$ Professor of Medicine, Director, Center of Excellence in Women's Health, University of Missouri-Kansas City School of Medicine, Departments of Biomedical and Health Informatics, Obstetrics and Gynecology and Community and Family Medicine

${ }^{2}$ Assistant Professor, University of Missouri-Kansas City School of Medicine, Departments of Obstetrics and Gynecology and Community and Family Medicine

${ }^{3}$ Clinical Associate Professor, University of Missouri-Kansas City School of Pharmacy, Division of Pharmacy Practice \& Administration

\begin{abstract}
Human papillomavirus (HPV) is necessary for the development of cervical cancer. Cervical cancer is the second most common cancer in women worldwide but $80 \%$ occurs in developing countries, not countries with Pap screening programs. Pap screening programs in industrialized countries have reduced the incidence of cervical cancer to 4-8/100,000 women. HPV vaccines may be a promising strategy for cervical cancer in women without access to screening programs. In industrialized countries, the benefit of HPV vaccines focuses on individual abnormal Pap test reduction not cancer prevention.
\end{abstract}

The focus of this review is to cover the side effects of Gardasil in perspective with the limited population benefit of cervical cancer reduction in countries with organized Pap screening programs. In addition, information about Gardasil benefits, risks and unknowns for individual patient decision making for vaccination is presented.

Gardasil offers protection against CIN 2+ lesions caused by HPV 16/18 and against genital warts caused by HPV $6 / 11$ for at least 5 years. Combining Gardasil with repeated cytology screenings may reduce the proportion of abnormal cytology screens and hence reduce the associated morbidity with the subsequent colposcopies and excisional procedures.

Keywords: Adverse effects; Cervical cancer; Duration of efficacy; HPV vaccine immunology; Gardasil

\section{Introduction}

Human papillomavirus (HPV) is a human carcinogen [1] which, when not immunologically mediated, causes cervical cancer [2]. HPV has also been linked to other mucosal cancers whose prevalences are orders of magnitude less common than cervical cancer [3]. There are over one hundred types of HPV which infect human epithelium with specific tropisms, of which 40 HPV types cause anogenital infections and fifteen high risk types are associated with cervical cancer $[4,5]$. However, in the general female US population, the prevalence of HPV 16 and 18 infections, considered the most frequent and most aggressive, is only $2.3 \%[6]$.

Ninety percent of HPV infections will be immunologically cleared by cell mediated immune responses within 3 years of infection. Five percent of high risk HPV infections persist beyond three years and progress into cervical intraepithelial neoplasia grade 2 and 3 (CIN 2/3), recognized cancer precursors [7]. Evolution from CIN 3 to invasive cervical cancer proceeds slowly with $20 \%$ of CIN 3 becoming invasive after 5 years, and $40 \%$ becoming invasive after 30 years [8].

Figure 1 details the prevalence of high risk HPV infections by age showing that the highest risk of infection occurs in the 16-24 year old group with elevation above baseline extending out to 35 years of age [9-16]. The onset of sexual activity coincides with the rapid increase in infection rates occurring in those 16 years and older.

It is the slow evolution from infection to CIN 3 to invasive cancer that has allowed the Pap early detection and treatment programs to reduce the incidence of cervical cancer from an unscreened 50$80 / 100,000$ women rate [3] to $4-8 / 100,000$ women in countries with screening programs $[17,18]$. Over eighty percent of the burden of cervical cancer, though, occurs in countries without population access to Pap early detection and treatment screening programs [3]. The estimated lowest incidence of cervical cancer with widespread coverage of the quadrivalent HPV vaccine (Gardasil ${ }^{\mathrm{TM}}$ ) for women without access to Pap screening, assuming vaccine lifetime immunity, is about $14 / 100,000$ women $[4,19,20]$. For women who continue the recommended program of repeated cytology screens, the estimated incidence of cervical cancer with widespread Gardasil coverage from cost effectiveness models, assuming lifetime vaccine efficacy, is no less than the incidence achieved by cytology screening alone $[18,20]$. Gardasil can only offer women participating in screening programs a $10 \%$ reduction in abnormal Pap tests with a resultant $20 \%$ decrease in colposcopies and a $42 \%$ decrease in treatments [21].

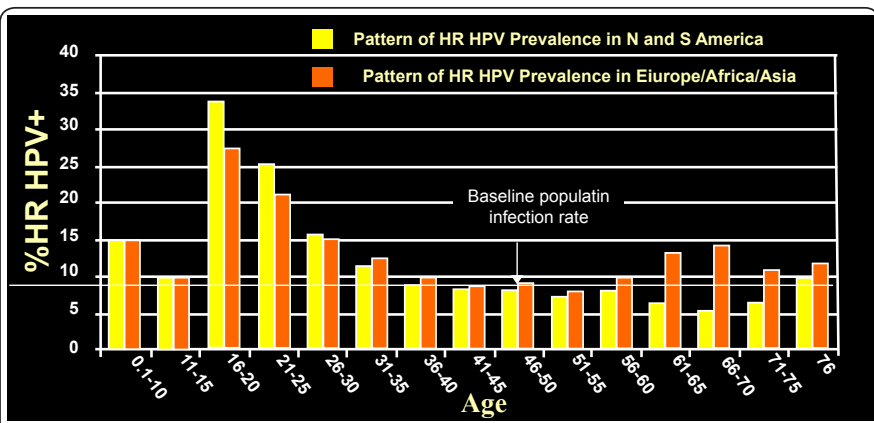

Figure 1: Prevalence of HR HPV infections by age group.

${ }^{*}$ Corresponding author: Diane M Harper, Professor of Medicine, Director, Cente of Excellence in Women's Health, University of Missouri-Kansas City School of Medicine, Departments of Biomedical and Health Informatics, Obstetrics and Gynecology and Community and Family Medicine, Truman Medical Center Lakewood 7900 Lee's Summit Road, Kansas City, MO 64139, USA, Tel: 816-4047107; Fax: 816-404-7142; E-mail: diane.m.harper@gmail.com

Received October 05, 2010; Accepted November 20, 2010; Published November 23, 2010

Citation: Harper DM, Vierthaler SL, Santee JA (2010) Review of Gardasil. J Vaccin Vaccinat 1: 107. doi:10.4172/2157-7560.1000107

Copyright: (c) 2010 Harper DM, et al. This is an open-access article distributed under the terms of the Creative Commons Attribution License, which permits unrestricted use, distribution, and reproduction in any medium, provided the original author and source are credited. 


\begin{tabular}{||l|l||}
\hline Material* & Amount \\
\hline HPV Type 6 L1 protein & $20 \mu \mathrm{gg}$ \\
\hline HPV Type 11 L1 protein & $40 \mu \mathrm{gg}$ \\
\hline HPV Type 16 L1 protein & $40 \mu \mathrm{g}$ \\
\hline HPV Type 18 L1 protein & $20 \mu \mathrm{g}$ \\
\hline Aluminum hydroxyphosphate sulfate adjuvant & $225 \mu \mathrm{g}$ \\
\hline Sodium chloride & $9.56 \mathrm{mg}$ \\
\hline Sodium borate & $35 \mu \mathrm{mg}$ \\
\hline L-histidine & $0.78 \mathrm{mg}$ \\
\hline Polysorbate 80 & $50 \mu \mathrm{g}$ \\
\hline Yeast protein & \\
\hline
\end{tabular}

Table 1: Composition of Gardasil.

\begin{tabular}{||l|l|l|l|l|}
\hline \hline HPV type & $\begin{array}{l}\text { Percentage of women losing } \\
\text { measurable type specific } \\
\text { antibody titers at month 18 after } \\
\text { initial Gardasil injection[32] }\end{array}$ & $\begin{array}{l}\text { Percentage of women losing } \\
\text { measurable type specific } \\
\text { antibody titers at month 36 after } \\
\text { initial Gardasil injection[32] }\end{array}$ & $\begin{array}{l}\text { Percentage of women losing } \\
\text { measurable type specific } \\
\text { antibody titers at month 60 after } \\
\text { initial Gardasil injection[32] }\end{array}$ & $\begin{array}{l}\text { Percentage of women losing } \\
\text { measurable type specific } \\
\text { antibody titers at 8.5 years after } \\
\text { initial Gardasil injection[75] }\end{array}$ \\
\hline 6 & 2 & 6 & 10 & - \\
\hline 11 & 2 & 4 & 9 & - \\
\hline 16 & 0 & 0 & 1 & 14 \\
\hline 18 & 14 & 24 & 35 \\
\hline
\end{tabular}

\begin{tabular}{|c|c|c|c|c|}
\hline Endpoint & Population & Vaccine Efficacy $(95 \% \mathrm{Cl})$ & Average time of follow up & Reference \\
\hline Persistent infection caused by HPV 6/11/16/18 & PPii & $96 \%(83,100)$ & $5 \mathrm{yr}$ & 76 \\
\hline CIN $1+$ caused by HPV 6/11/16/18T & $\mathrm{PE}$ & $100 \%(13,100)$ & $40 \mathrm{mo}$ & 28 \\
\hline CIN 2+ caused by HPV 16/18 & PPSP & $98 \%(94,100)$ & 3.5 yrs & 33 \\
\hline CIN 2+ caused by HPV $16 / 18$ & USP & $95 \%(85,99)$ & $3.5 \mathrm{yrs}$ & 33 \\
\hline CIN 2+ caused by HPV 16/18 & ITT & $44 \%(26-58)$ & $3.5 \mathrm{yrs}$ & 33 \\
\hline CIN 2+ caused by any HPV type & ITT & $18 \%(7,28)$ & $3.5 \mathrm{yrs}$ & 33 \\
\hline CIN 2+ caused by any HPV type & NPS & $43 \%(24,57)$ & $3.6 \mathrm{yrs}$ & 21 \\
\hline VIN 2/3 caused by HPV 16/18 & PP & $100 \%(56,100)$ & $44 \mathrm{mo}$ & 33 \\
\hline ValN $2 / 3$ caused by HPV $16 / 18$ & PP & $100 \%(50,100)$ & $44 \mathrm{mo}$ & 33 \\
\hline VIN 2/3 caused by any HPV type§ & ITT & $50 \%(9,73)$ & $44 \mathrm{mo}$ & 33 \\
\hline ValN 1 caused by HPV 6/11/16/18† & PP & $100 \%(31,100)$ & $36 \mathrm{mo}$ & 77 \\
\hline VIN 1 , VaIN 1 or condyloma caused by any HPV & ITT & $41 \%(28,51)$ & $36 \mathrm{mo}$ & 77 \\
\hline Condyloma caused by HPV 6/11/16/18 & PP & $99 \%(96,100)$ & $44 \mathrm{mo}$ & 33 \\
\hline Condyloma caused by any HPV type & PP & $83 \%(74,89)$ & $44 \mathrm{mo}$ & 33 \\
\hline Condyloma caused by HPV 6/11/16/18 & $\mathrm{PE}$ & $100 \%(28,100)$ & $40 \mathrm{mo}$ & 28 \\
\hline Male condyloma caused by HPV 6/11/16/18 & PPE & $89 \%(66-98)$ & $29 \mathrm{mo}$ & 34 \\
\hline Male condyloma caused by HPV $6^{*}$ & PPE & $84 \%(47,97)$ & $29 \mathrm{mo}$ & 34 \\
\hline Male condyloma caused by HPV $11^{*}$ & PPE & $91 \%(38,100)$ & $29 \mathrm{mo}$ & 34 \\
\hline
\end{tabular}

PPii means per-protocol: seronegative and PCR negative to HPV 6,11,16, 18 at baseline, remained PCR negative for vaccine relevant type through one month post dose 3 and received three doses within one year; cases were counted starting one month after three doses given.

PPSP means per protocol susceptible population: for those women who were seronegative and PCR negative for the vaccine related HPV types at study entry regardless of entry cytology results, remained PCR negative for the vaccine relevant HPV types through one month after receipt of the third injection; cases counted one month after three doses given.

USP means unrestricted susceptible population: for those women who were seronegative and PCR negative for the vaccine related HPV types at study entry regardless of entry cytology results, received one or more injections, cases counted from the first day after the first injection.

ITT means intention to treat population: regardless of serostatus or HPV DNA PCR status to vaccine relevant HPV types at study entry, regardless of entry cytology, regardless of timing and number of injections received, cases were counted from day 1 after the first injection.

NPS means naive population simulation: women were seronegative to HPV 6/11/16/18 and PCR negative to HPV 6/11/16/18/31/33/35/39/45/51/52/56/58/59 at baseline, had a normal Pap at baseline, received at least one injection, had at least one follow up visit; cases counted after day 1.

PP means Per Protocol: women were seronegative at baseline and PCR negative for each type Day 1 through Month 7, regardless of entry cytology; cases were counted from the first day after 30 days after the third injection.

PPE means per protocol for efficacy in male trials: seronegative and PCR negative to the relevant HPV type at Day 1 , Free of infection with the relevant HPV type through Month 7, Received all 3 doses; cases were counted from the first day after 30 days after the third injection.

PE means previously exposed population: women who were seropositive for HPV 6/11/16/18 and were PCR negative for HPV 6/11/16/18 at baseline.

*Male condyloma caused by HPV 16 or 18 were not statistically significant

†VIN 1 caused by HPV 6/11/16/18 was not statistically significant

$\S$ Vain $2 / 3$ caused by any HPV type was not statistically significant

ๆCIN 2+, CIN 3+, AIS. VIN 1, VIN 2+, VaIN 1, ValN 2+ caused by HPV 6/11/16/18 were not statistically significant

Table 3: Significant Efficacies for Gardasil by Endpoint, Population and Time of Follow Up. 


\section{Mechanism of Action}

The L1 virus like particles (VLPs) specific to HPV 16 and 18 as well as the genital wart causing HPV 6 and 11 comprise the 120 microgram antigenic protein load in each Gardasil dose. Each $0.5 \mathrm{ml}$ dose also contains aluminum hydroxyphosphate sulfate and polysorbate-80; the recombinant vaccine is synthesized in Saccharomyces cerevisiae (brewer's yeast) (Table 1). Prior allergic responses to these components preclude vaccine administration. The protein content in Gardasil may be linked to the autoimmune demyelinating neurologic adverse events that have been reported, and are feared more common in girls than boys $[22,23]$.

All anogenital HPV infections are intraepithelial, highly successful dendritic cell evaders that take years to be cleared by $T$ cell mediated immunity $[7,24,25]$, only stimulating low natural infection antibody titers in about half of women infected [26]. These low titers wane within a few years [27] and most do not confer long term protection [28] against future same type infections.

Gardasil is prophylactic in that it induces high initial serum HPV type specific antibodies. The antibodies neutralize the infecting HPV virion by preventing endocytosis into the epithelial basal cells. Antibodies reach the denuded basement membrane in one of two ways: a continuous transudes from the dermal capillary network up through the intact basement membrane or through an exudate which is caused from tissue injury to the cervical epithelium exposing the basement membrane to HPV virions. Both methods of antibody localization require high antibody titers to neutralize infective type specific virions.

Gardasil induced antibody titers are no longer measurable for HPV 6, 11, 16 and 18 over time (Table 2). HPV 18 antibodies are lost most quickly and in highest quantities [29]. This is one factor that leads to the belief that Gardasil booster injections may be necessary [30] for actual cancer prevention [31].

Gardasil will not prevent cervical cancer unless its efficacy persists for at least 15 years [18]. Vaccinating targeted age group adolescents at 11-12 years without a guarantee of protection until they exit the age range for highest acquisition of high risk HPV infections is expensive with very limited, if any, clinical benefit. To date, there is evidence of protection against CIN $1+$ disease caused by HPV 16/18 in seropositive women who are DNA negative for vaccine types at the time of vaccination, but, due to small study numbers, not against CIN $2+$ disease caused by HPV 16/18 [28].

Therapeutic efficacy was conclusively disproven among the population of women DNA positive for a vaccine relevant type at baseline whose CIN lesion did not regress during the three years of the FUTURE I trial, nor was progression to invasive cancer accelerated by HPV vaccination [32].

\section{Clinical applications}

Final study results from the phase II trials (5 years) and the phase III pivotal trials (44 months) in women indicate efficacies for specific endpoints and specific populations of women listed in Table 3. One of the most important outcomes is that the maximum reported duration of efficacy is 5 years. Cervical cancer prevention is not possible without demonstration of efficacy of at least 15 years. Therefore, a clinical balance must be struck: Gardasil must be administered to cover the five riskiest years for high risk HPV acquisition as five years is the known duration of protection, but if administered too early before sexual activity, there is a risk of vaccine waning with no long term protection; and if administered too late, after exposure, there is no efficacy for prevention of recurrent/repeat same type HPV infections. In the latter case, there will still be efficacy for types to which the woman has not yet been exposed, providing both vaccine immunogenicity and efficacy. This information can allow timing of vaccination to be tailored to the individual girl/woman for her maximum benefit.

If vaccination occurs prior to wart exposure, Gardasil prevents most genital warts for an average of 44 months in women [33] and 29 months in men [34]. Similarly to CIN 2+ protection, if Gardasil is given at young ages when girls are presumed seronegative and PCR negative for HPV 6/11/16/18, the duration of protection against genital warts may be insufficient to protect girls when they become most vulnerable to HPV infection. While the point efficacy for wart protection is $100 \%$, the $95 \%$ confidence intervals, $28-100$, are quite broad for reassuring high levels of wart prevention. Gardasil studies have shown that antibody titers induced by natural infection do not prevent future same type specific HPV infections [28]. Gardasil induced antibody titers for HPV 6 and 11 return to natural infection titer levels one year after vaccination [29]. There is evidence that Gardasil is effective at preventing condyloma in girls/women who are seropositive but DNA negative for HPV 6 and 11 at the time of their initial vaccination [28]. This may extend the clinical time frame for girls/women to gain protection against genital warts.

The small portion of vulvar and vaginal intraepithelial neoplasias which are attributed to HPV [27] can be partially prevented by Gardasil for a limited time. There are no data to date supporting prevention of penile and anal lesions attributed to HPV 16/18 by Gardasil [34]. There is early evidence of potential efficacy against a composite grouping of anal intraepithelial neoplasias of all grades caused by all four vaccine related HPV types, without specifically showing prevention against AIN 2+ caused by HPV 16/18 in men having sex with men [35].

\section{Safety Evaluation}

\section{Safety in clinical studies}

The proof of principle report for the HPV 16 monovalent vaccine given to 1194 women 16-23 years old presages the adverse events to continue to be reported in the subsequent development of Gardasil [36]. Vaccine related pain at injection was reported in $86 \%$ of recipients, with $40 \%$ reporting a systemic event, most often being headache.

The phase II study, testing the quadrivalent HPV vaccine, report of 272 vaccinated women 16-23 years old followed for 3 years showed $86 \%$ of women had local injection site reactions (vs. $77 \%$ of placebos), $38 \%$ of vaccinated women had systemic adverse reactions due to the vaccine (vs. $33 \%$ of placebos), and $1 \%$ of women receiving vaccine and placebo reported serious adverse events (vs. 1\% of placebos) [37]. The statistically significant local injection site reactions included pain $(85 \%)$ and induration (28\%) of mild or moderate intensity with less adverse reactions in those women already seropositive at vaccination [38].

The phase III report of 529 vaccinated women in FUTURE I (15-24 years old) and 448 vaccinated women in FUTURE II (15-26 year old) reinforced pain, erythema and induration as significant local injection site reactions within 5 days of administration. Fever occurred 3 to 11 times more often in the vaccinated FUTURE I women than those receiving placebo. Among these 977 women followed for safety in these pivotal trials, no indications of serious adverse events were reported $[32,39]$. 
Safety studies were reported in other age ranges for a very limited follow up time. Adolescent girls (501, aged 10-15 years) and boys (500, aged 10-15 years) were reported to have fevers significantly more frequently within 5 days of vaccination than women $16-23$ years old, but less pain and erythema for local injection site reactions [40]. A condensation of five Gardasil trials including girls/women 9-26 years of age followed for an average of 3.6 years were analyzed for safety, relying on passive memory recall of adverse events reported at six month intervals for surveillance beyond the initial 15 day vaccine report card active data collection; little new information was gleaned from this composite analysis [41]. In a report of vaccinated women 24-45 years old, injection site reactions occurred more frequently in vaccinated than placebo recipients [42]. No follow up past 15 days was reported.

The safety of Gardasil in combination with other vaccines was reported in three trials. The concomitant administration of Gardasil and Recombivax HBR (recombinant Hepatitis B surface antigen with $500 \mathrm{mcg} / \mathrm{ml}$ of aluminum adjuvant [Merck Research Laboratories, West Point, PA, USA]) [43] was given to 468 women 16 -23 years old of whom 93\% experienced at least one adverse event within 15 days of the injection: $90 \%$ had an injection site reaction, and $17 \%$ experienced headaches and fevers. The injection site reactions occurred significantly more frequently if both vaccines were administered concomitantly (different sites/arms) than if either single vaccine was partnered with placebo (administered in different sites/arms). No serious adverse events were reported for the 15 day time frame. No follow up past 15 days was reported.

In 10-17 year old girls, Gardasil concomitantly administered with Menactra (meningococcal polysaccharide conjugate of serogroups A, C, Y, and W135 [Sanofi Pasteur Inc, Lyon,France]) and Adacel (tetanus, diphtheria,and acellular pertussis [Sanofi Pasteur Inc]) showed increased injection site reactions within 15 days of administration significantly more often than when Menactra or Adacel were given alone one month later [44]. The three vaccines together nearly doubled the proportion of girls experiencing injection site reactions. No long term follow up was reported.

Among 295 girls and 124 boys aged 11-17 years, Gardasil was administered concomitantly with Repevax (diphtheria, tetanus, pertussis (acellular), and poliomyelitis (inactivated) vaccine [Sanofi Pasteur Inc, Lyon, France]) at the first vaccination [45]. As in the Menactra/Adacel trial, the 15 day follow up after the concomitant administration of Repevax and Gardasil showed significantly more injection site and systemic reports of adverse events than if the two vaccines had been given independently. No follow up data beyond 15 days were reported.

Reproductive adverse events were reported in the trials of 15-45 year old women $[40,46]$. Specifically, fetal malformations and death were evaluated in those pregnancies which occurred within 30 days of receiving Gardasil. There were fetal anomalies reported for both the vaccine and placebo recipients; initial statistical significance for Gardasil-linked-fetal-anomalies vanished when one additional report of a fetal anomaly in a placebo recipient occurred. This shows that the significance of early pregnancy events within 30 days of Gardasil injection is extremely sensitive to the number of events in the placebo and Gardasil arms [46].

The prevalence of schizencephaly and anencephaly in the general population is $1.5 / 100,000$ and $1.1 / 10,000$, respectively [47]. In the first report of the pregnancy registry, two cases of schizencephaly and two cases of anencephaly occurred in fetuses of the 451 women who received Gardasil within 30 days of conception, a rate higher than the general population [47]. The pregnancy registry reports for Gardasil will continue to update the frequency of potential teratogenic adverse events. At this time Gardasil has not been deemed causative for teratogenic adverse events [46,47]. There are no recommendations for or against Gardasil administration during periods of active attempts at conception.

\section{Postmarketing data}

In general, at this time Gardasil is considered safe for most women by federal and international regulatory bodies period. The studies Merck has published indicate little safety concern among the about 12,000 women vaccinated in the randomized controlled trials.

The cases from the Vaccine Adverse Events Reporting System (VAERS) after the first 18 months of Gardasil availability in the US were published by Slade [48]. 68\% of the adverse events were reported to VAERS by Merck, and of these reports $89 \%$ had insufficient information to evaluate the adverse outcome, causing these cases to be omitted from Slade's analysis.

Syncope was reported at vaccine distribution levels of 8.2 cases/100,000 doses distributed (29\% of the VAERS reports) and was reported to have resulted in falls, head injuries, facial and teeth fractures, concussions, intracranial hemorrhages and lacerations. A case report hypothesizes a different mechanism of postural hypotension other than a psychogenic reaction causing syncope $[49,53]$. This recognized adverse event was addressed by regulatory bodies suggesting that all vaccinees be sitting or prone for 15 minutes after vaccination.

Venous thromboembolism (VTE) was reported at 0.2 cases/100,000 doses distributed resulting in 4 deaths among the 19 cases of pulmonary embolus. $90 \%$ of the cases of VTE had known risk factor including oral contraceptive use, obesity, and immobility. While these co-factors are important, other interactions of the VLPs with molecules such as the heparin binding motif are being actively investigated as a precipitator of clotting in those genetically predisposed.

Other serious adverse events reported at 3.4 cases $/ 100,000$ doses distributed included pancreatitis, transverse myelitis, anaphylaxis, hypersensitivity, auto-immune disorders, juvenile ALS like syndromes, Guillain Barré Syndrome, and death.

In addition to the VAERS compilation, other sources of safety include case reports published by independent scientists and clinicians detailing the clinical course and temporal relationship after 50 million doses of Gardasil had been distributed [50]. Case reports are the weakest link of causality, yet are the first opportunity to identify a problem that controlled trials are incapable of detecting. Recognition of side effects of drugs/vaccines is usually based on the identification of multiple identical observations by independent physicians [50]. Unexpected adverse effects are by definition due to unknown mechanisms, and further accumulation of case reports can provide sufficient evidence for causation linkage of the adverse event to the vaccine. Observational case studies are more suitable for detecting rare or late adverse effects of vaccines, and are more likely to provide an indication of what is achieved in daily medical practice [51]. As a consequence, published case reports remain a valid and efficient source for signal generation and are of great value for safety issues [52].

Independent scientists continue to publish reports of patients 
who have had autoimmune demyelinating neurologic sequelae after Gardasil administration, resulting in blindness, paralysis, and death [22,54-61]. Others have reported lipoatrophy [62], aluminum granuloma [63], supraclavicular adenopathy [64], anaphylaxis [65], pancreatitis [66], immune thrombocytopenia purpura [67] and erythema multiforme [68], all potentially related to an immunologic reaction. Yet, although autoimmune neurologic sequelae after Gardasil administration have been the most lethal of events reported, because their frequency is less than $1 / 10,000$, the significant frequency at which adverse events are considered 'rare' [69], regulatory authorities do not have to change their safety guidance. Guillain-Barré Syndrome (GBS), a reported serious adverse event after vaccination, occurs at a baseline rate in the US of 5 per million persons [70], a rate which is much different from the $1 / 10,000$ threshold being used to decide if Gardasil is associated with GBS. As of May, 2009, one claim filed with the US National Vaccine Injury Compensation Program against Gardasil for damages caused by the vaccine has already been awarded [71].

\section{Safety in special populations}

Gardasil's interaction with some co-morbid clinical diseases or genetically predisposed tendencies could be life-threatening for some girls. Hence there are studies registered to evaluate the effect of Gardasil on young girls with systemic lupus erythematosus, inflammatory bowel disease, juvenile idiopathic arthritis, juvenile dermatomyositis, solid organ transplants, HIV/AIDS, and chronic illnesses [72].

\section{Comparison with safety of other methods to prevent same disease}

Gardasil was developed as an adjunct to Pap screening in countries with an organized cervical cytology screening program. Cytology screening programs are quite successful and cost effective compared to no prevention strategy. Likewise, cytology screening programs are more cost effective than HPV vaccination alone or vaccination in combination with screening $[20,73]$. If vaccinated women choose to skip their Pap screening, cervical cancer incidence will not be reduced, and all cost effectiveness of HPV vaccination will be lost. This detrimental outcome is worse if vaccine protection proves to be only 15 years $[20]$.

In countries without universal access to lifetime Pap screening where the baseline incidence of cervical cancer is $50-80 / 100,000$ women, then Gardasil, under the unproven assumption of lifetime immunity, is estimated to reduce the incidence to $14 / 100,000$ at best. This population benefit could be real and could save lives in the setting of no access to screening programs.

In countries with cytology screening programs, HPV vaccination could theoretically address some of the limitations of the screening programs. If a vaccine were to be developed which covered all high risk HPV types, provided lifetime immunity, and allowed infant vaccination, then Pap screening could be retired and cervical cancer would be reduced to the lowest levels possible. With the current formulation of Gardasil, vaccinated women still need serial cytology screenings, are still subject to both false negative and false positive cytology results and their subsequent diagnostic workups, and will still have anxiety and psychosocial trauma from having an abnormal cytology result, albeit somewhat abated by the reduction in abnormal Pap tests vaccination can provide. Likewise, Gardasil can only lessen the reproductive morbidity associated with excisional treatments of CIN 2+ disease, not eliminate it.

\section{Conclusions}

The primary question to ask about the decision to vaccinate with Gardasil is, "Is there good evidence that this new vaccine is likely to make my patient live longer or better compared with the available alternatives?" [74]. We do not know how long the vaccine will last, the HPV types covered by the vaccine are limited, and the very safe alternative of Pap screening with early detection and treatment is a proven successful program. Gardasil is not likely to extend a woman's life in countries with cytology screening, but it may allow her to experience fewer abnormal Pap tests and their subsequent workup.

\section{Conflict of Interest}

JAS: Nothing to disclose. SLV: Nothing to disclose.

$\mathrm{DMH}$ : The institutions at which I have conducted HPV vaccine trials have received funding to support clinical trials on the vaccines discussed herein from Merck and GlaxoSmithKline.

I have also received honoraria for speaking and for participation on advisory boards from Merck and GlaxoSmithKline.

\section{Acknowdgemant}

This work was supported by NIH grant 1P50CA105632 of Electra Paskett.

\section{References}

1. National Toxicology Program (2005) NTP 11th Report on Carcinogens. Rep Carcinog 11: 1-A32.

2. Zur Hausen $\mathrm{H}$ (2009) Papillomaviruses in the causation of human cancers - a brief historical account. Virology 384: 260-265

3. Parkin DM (2006) The global health burden of infection-associated cancers in the year 2002. Int J Cancer 118: 3030-3044

4. de Sanjosé S, Diaz M, Castellsagué X, Clifford G, Bruni L, et al. (2007)Worldwide prevalence and genotype distribution of cervical human papillomavirus DNA in women with normal cytology: a meta-analysis. Lancet Infect Dis 7: 453-459.

5. Khan MJ, Castle PE, Lorincz AT, Wacholder S, Sherman M,et al. (2005) The elevated 10-year risk of cervical precancer and cancer in women with human papillomavirus (HPV) type 16 or 18 and the possible utility of type-specific HPV testing in clinical practice. J Natl Cancer Inst 97: 1072-1079.

6. Dunne EF, Unger ER, Sternberg M, McQuillan G, Swan DC, et al. (2007) Prevalence of HPV Infection among females in the United States. JAMA 297 813-819.

7. Schiffman M, Rodríguez AC (2008) Heterogeneity in CIN3 diagnosis. Lance Oncol 9: 404-406.

8. McCredie MR, Sharples KJ, Paul C, Baranyai J, Medley G, et al. (2008) Natura history of cervical neoplasia and risk of invasive cancer in women with cervical intraepithelial neoplasia 3: a retrospective cohort study. Lancet Oncol 9: 425434

9. Cubie HA, Plumstead M, Zhang W, de Jesus O, Duncan LA, et al. (1998) Presence of antibodies to human papillomavirus virus-like particles (VLPS) in 11-13-year-old schoolgirls. J Med Virol 56: 210-216.

10. Schiffman M, Kjaer SK (2003) Chapter 2: Natural history of anogenital human papillomavirus infection and neoplasia. J Natl Cancer Inst Monogr 31: 14-19.

11. Rintala MA, Grénman SE, Järvenkylä ME, Syrjänen KJ, Syrjänen SM (2005) High-risk types of human papillomavirus (HPV) DNA in oral and genital mucosa of infants during their first 3 years of life: experience from the Finnish HPV Family Study. Clin Infect Dis 41: 1728-1733.

12. Smith EM, Ritchie JM, Yankowitz J, Swarnavel S, Wang D, et al. (2004) Human papillomavirus prevalence and types in newborns and parents: concordance and modes of transmission. Sex Transm Dis 31: 57-62.

13. Smith EM, Johnson SR, Ritchie JM, Feddersen D, Wang D, et al. (2004) Persistent HPV infection in postmenopausal age women. Int J Gynaecol Obstet 87: 131-137.

14. Bandyopadhyay S, Sen S, Majumdar L, Chatterjee R (2003) Human papillomavirus infection among Indian mothers and their infants. Asian Pac Cancer Prev 4: 179-184. 
15. Stone KM, Karem KL, Sternberg MR, McQuillan GM, Poon AD, et al. (2002) Seroprevalence of human papillomavirus type 16 infection in the United States. $\mathrm{J}$ Infect Dis 186: 1396-402.

16. Dunne EF, Karem KL, Sternberg MR, Stone KM, Unger ER, et al. (2005) Seroprevalence of human papillomavirus type 16 in children. J Infect Dis191: 1817-1819.

17. http://apps.nccd.cdc.gov/uscs/cancersbyraceandethnicity.aspx [accessed 20 Nov 2010]

18. Barnabas RV, Laukkanen P, Koskela P, Kontula O, Lehtinen M, et al. (2006) Epidemiology of HPV 16 and cervical cancer in Finland and the potential impact of vaccination: Mathematical modeling analyses. PLoS Med 3: e138.

19. Harper DM (2009) Currently approved prophylactic HPV vaccines. Expert Rev Vaccines 8: 1663-1679.

20. Berkhof J, Bogaards J, Coupé V, Meijer C (2010) Modeling the influence of screening uptake on the future incidence of cervical cancer and the costeffectiveness of HPV vaccination. Abstract number 464. 26th International Papillomavirus Conference. July 3-8, Montreal Canada.

21. Muñoz N, Kjaer SK, Sigurdsson K, Iversen OE, Hernandez-Avila M, et al.(2010) Impact of human papillomavirus (HPV)-6/11/16/18 vaccine on all HPVassociated genital diseases in young women. J Natl Cancer Inst 102: 325-339.

22. Sutton I, Lahoria R, Tan I, Clouston P, Barnett M (2009) CNS demyelination and quadrivalent HPV vaccination. Mult Scler 15: 116-119.

23. Klein SL, Jedlicka A, Pekosz A (2010) The Xs and $Y$ of immune responses to viral vaccines. Lancet Infect Dis 10: 338-349.

24. Stanley M (2006) Immune responses to human papillomavirus. Vaccine 24 Suppl 1:S16-22.

25. Rodríguez AC, Schiffman M, Herrero R, Hildesheim A, Bratti C, et al (2010) Longitudinal study of human papillomavirus persistence and cervical intraepithelial neoplasia grade 2/3: critical role of duration of infection. J Natl Cancer Inst 102: 315-324.

26. Carter JJ, Koutsky LA, Hughes JP, Lee SK, Kuypers J, et al. (2000) Comparison of human papillomavirus types 16,18 and 6 capsid antibody responses following incident infection. J Infect Dis 181: 1911-1919.

27. Ho GY, Bierman R, Beardsley L, Chang CJ, Burk RD (1998) Natural history of cervicovaginal papillomavirus infection in young women. N Engl J Med 338 423-428

28. Olsson WE, Kjaer SK, Sigurdsson K, Iversen OE, Hernandez-Avila M, et al. (2009) Evaluation of quadrivalent HPV 6/11/16/18 vaccine efficacy against cervical and anogenital disease in subjects with serological evidence of prior vaccine type HPV infection. Hum Vaccin 5: 696-704.

29. Olsson SE, Villa LL, Costa RL, Petta CA, Andrade RP, et al. (2007) Induction of immune memory following administration of a prophylactic quadrivalent human papillomavirus (HPV) types 6/11/16/18 L1 virus-like particle (VLP) vaccine. Vaccine 2: 4931-4939.

30. Michaels KB, zur Hausen H (2009) HPV vaccine for all. Lancet 374: 268-270.

31. Kim JJ, Goldie SJ (2008) Health and economic implication of HPV vaccination in the United States. N Engl J Med 359: 821-832.

32. Garland SM, Hernandez-Avila M, Wheeler CM, Perez G, Harper DM, et al. (2007) Quadrivalent vaccine against human papillomavirus to prevent anogenital diseases. N Engl J Med 356: 1928-1943.

33. http://www.fda.gov/downloads/BiologicsBloodVaccines/Vaccines/ ApprovedProducts/UCM111274.pdf

34. http://www.fda.gov/downloads/BiologicsBloodVaccines/Vaccines/ ApprovedProducts/UCM190978.pdf. Giuliano AR, Palefsky JM, Goldstone S, Moreira ED, Penny ME, et al. (2011) Efficacy of Quadrivalent HPV Vaccine against HPV Infection and Disease in Males. N Engl J Med 364: 401-411.

35. Palefsky J (2010) Efficacy of the quadrivalent HPV vaccine to prevent anal intraepithelial neoplasia among young men who have sex with men. Abstract 465. Presented at 2010 HPV International Papillomavirus Conference, July 3-8, Montreal, Canada.

36. Koutsky LA, Ault KA, Wheeler CM, Brown DR, Barr E, et al. (2002) A controlled trial of a human papillomavirus type 16 vaccine. N Engl J Med 347: 1645-1651.
37. Villa LL, Costa RL, Petta CA, Andrade RP, Ault KA, et al. (2005) Prophylactic quadrivalent human papillomavirus (types 6, 11, 16, and 18) L1 virus-like particle vaccine in young women: a randomised double-blind placebo-controlled multicentre phase II efficacy trial. Lancet Oncol 6: 271-278.

38. Villa LL, Ault KA, Giuliano AR, Costa RL, Petta CA, et al. (2006) Immunologic responses following administration of a vaccine targeting human papillomavirus Types 6, 11, 16, and 18. Vaccine 24: 5571-5583.

39. Koutsky LA for the FUTURE II Study Group (2007) Quadrivalent Vaccine against Human Papillomavirus to Prevent High-Grade Cervical Lesions. N Engl J Medicine 356: 1915-1927.

40. Block SL, Nolan T, Sattler C, Barr E, Giacoletti KE, et al. (2006) Comparison of the immunogenicity and reactogenicity of a prophylactic quadrivalent human papillomavirus (types 6, 11, 16 and 18) L1 virus-like particle vaccine in male and female adolescents and young adult women. Pediatrics 118: 2135-2145.

41. Block SL, Brown DR, Chatterjee A, Gold MA, Sings HL, et al. (2010) Clinical trial and post-licensure safety profile of a prophylactic human papillomavirus (types 6, 11, 16 and 18) I1 virus-like particle vaccine. Pediatr Infect Dis J 29: 95-101.

42. Muñoz N, Manalastas R Jr, Pitisuttithum P, Tresukosol D, Monsonego J, et al. (2009) Safety, immunogenicity, and efficacy of quadrivalent human papillomavirus (types $6,11,16,18$ ) recombinant vaccine in women aged $24-45$ years: a randomised, double-blind trial. Lancet 373: 1949-1957.

43. Wheeler CM, Bautista OM, Tomassini JE, Nelson M, Sattler CA, et al. (2008) Safety and immunogenicity of co-administered quadrivalent human papillomavirus (HPV)-6/11/16/18 L1 virus-like particle (VLP) and hepatitis B (HBV) vaccines. Vaccine 26: 686-696.

44. Reisinger KS, Block SL, Collins-Ogle M, Marchant C, Catlett M, et al. (2010) Safety, tolerability, and immunogenicity of gardasil given concomitantly with Menactra and Adacel. Pediatrics 125: 1142-1151.

45. Vesikari T, Van Damme P, Lindblad N, Pfletschinger U, Radley D, et al. (2010) An open-label, randomized, multicenter study of the safety, tolerability, and immunogenicity of quadrivalent human papillomavirus (types 6/11/16/18 vaccine given concomitantly with diphtheria, tetanus, pertussis, and poliomyelitis vaccine in healthy adolescents 11 to 17 years of age. Pediat Infect Dis J 29: 314-318.

46. Garland SM, Ault KA, Gall SA, Paavonen J, Sings HL, et al. (2009) Pregnancy and infant outcomes in the clinical trials of a human papillomavirus type 6/11/16/18 vaccine: a combined analysis of five randomized controlled trials Obstet Gynecol 114: 1179-1188.

47. Dana A, Buchanan KM, Goss MA, Seminack MM, Shields KE, et al. (2009) Pregnancy outcomes from the pregnancy registry of a human papillomavirus type 6/11/16/18 vaccine. Obstet Gynecol 114: 1170-1178.

48. Slade BA, Leidel L, Vellozzi C, Woo EJ, Hua W, et al. (2009) Postlicensure safety surveillance for quadrivalent human papillomavirus recombinant vaccine. JAMA 302: 750-757.

49. Blitshteyn S (2010) Postural tachycardia syndrome after vaccination with Gardasil. Eur J Neurol 17: e52.

50. Vandenbroucke JP (2001) In defense of case reports and case series. Ann Intern Med 134: 330-334.

51. Vandenbroucke JP (2006) Case reports of suspected adverse drug reactions: Case reports were dismissed too quickly. BMJ 332: 488.

52. Agha R, Rosin RD (2010) Time for a new approach to case reports. Int J Surg 8: $330-332$.

53. Centers for Disease Control and Prevention (CDC) (2008) Syncope after vaccination--United States, January 2005-July 2007. MMWR Morb Mortal Wkly Rep 57: 457-460.

54. Kang LW, Crawford N, Tang ML, Buttery J, Royle J, et al. (2008) Hypersensitivity reactions to human papillomavirus vaccine in Australian schoolgirls: retrospective cohort study. BMJ 337: a2642.

55. Debeer P, De Munter P, Bruyninckx F, Devlieger R (2008) Brachial plexus neuritis following HPV vaccination. Vaccine 26: 4417-4419.

56. Lower J (2008) Two unclear cases of death. Can we still recommend HPV vaccination? MMW Fortschr Med 150: 6 .

57. Lawrence G, Gold MS, Hill R, Deeks S, Glasswell A, et al. (2008) Annual report: surveillance of adverse events following immunisation in Australia, 2007. Commun Dis Intell 32: 371-387. 
58. Wildemann B, Jarius S, Hartmann M, Regula JU, Hametner C, et al. (2009) Acute disseminated encephalomyelitis following vaccination against human papillomavirus. Neurology 72: 2132-2133.

59. McCarthy JE, Filiano J (2009) Opsoclonusmyoclonus after human papilloma virus vaccine in a pediatric patient. Parkinsonism Relat Disord 15(10):792-794.

60. Cohen SM (2009) Multiple Evanescent White Dot Syndrome After Vaccination for Human Papilloma Virus and Meningococcus. J Pediatr Ophthalmol Strabismus 25: 1-3.

61. Khalifa YM, Monahan PM, Acharya NR (2010) Ampiginous choroiditis following quadrivalent human papilloma virus vaccine. $\mathrm{Br} \mathrm{J}$ Ophthalmol 94: 137-139.

62. Ojaimi S, Buttery JP, Korman TM (2009) Quadrivalent human papillomavirus recombinant vaccine associated lipoatrophy. Vaccine 27: 2876-2878.

63. Marsee DK, Williams JM, Velazquez EF (2008) Aluminum granuloma after administration of the quadrivalent human papillomavirus vaccine. Report of a case. Am J Dermatopathol 30: 622-624.

64. Studdiford J, Lamb K, Horvath K, Altshuler M, Stonehouse A (2008) Development of unilateral cervical and supraclavicular lymphadenopathy after human papillomavirus vaccination. Pharmacotherapy 28: 1194-1197.

65. Brotherton JM, Gold MS, Kemp AS, Mclntyre PB, Burgess MA, et al. (2008) Anaphylaxis following quadrivalent human papillomavirus vaccination. CMA 179: 525-533.

66. Das A, Chang D, Biankin AV, Merrett ND (2008) Pancreatitis following human papillomavirus vaccination. Med J Aust 189: 178

67. Pugnet G, Ysebaert L, Bagheri H, Montastruc JL, Laurent G (2009) Immune thrombocytopenia purpura following human papillomavirus vaccination. Vaccine 27: 3690.
68. Katoulis AC, Liakou A, Bozi E, Theodorakis M, Alevizou A, et al. (2010) Erythema multiforme following vaccination for human papillomavirus. Dermatology 220 : 60-62.

69. http://whqlibdoc.who.int/aide-memoire/a87773_eng.pdf [accessed 20 Nov 2010].

70. Centers for Disease Control and Prevention (CDC) (2010) Preliminary Results: Surveillance for Guillain-Barré Syndrome after Receipt of Influenza A (H1N1) 2009 Monovalent Vaccine --- United States, 2009--2010. MMWR Morb Morta Wkly Rep 59: 657-661.

71. http://www.hrsa.gov/vaccinecompensation/statistics_report.htm\#claims_filed [accessed 20 Nov 2010].

72. http://clinicaltrials.gov/ct2/results?term=Gardasil+ [accessed 20 Nov 2010].

73. Coupe VMH, van Ginkel J, de Melker HE, Snijders PJ, Meijer CJ, et al. (2009) HPV16/18 vaccination to prevent cervical cancer in The Netherlands: Modelbased cost-effectiveness. Int J Cancer 124: 970-978.

74. Pegler S, Underhill J (2010) Evaluating the Safety and Effectiveness of New Drugs. Am Fam Physician 82: 53-57.

75. Rowhani-Rahbar A, Mao C, Hughes JP, Alvarez FB, Bryan JT, et al. (2009) Longer term efficacy of a prophylactic monovalent human papillomavirus type 16 vaccine. Vaccine 27: 5612-5619.

76. Villa LL, Costa RL, Petta CA, Andrade RP, Paavonen J, et al. (2006) High sustained efficacy of a prophylactic quadrivalent human papillomavirus types 6/11/16/18 L1 virus-like particle vaccine through 5 years of follow-up. $\mathrm{Br} \mathrm{J}$ Cancer 95: 1459-1466.

77. http://www.fda.gov/downloads/BiologicsBloodVaccines/Vaccines/ ApprovedProducts/UCM111287.pdf-[accessed 20 Nov 2010]. 